Volume 14 - Número 2 - ago/dez de 2019

\title{
EXECUÇÃO DOS GESTOS EMBLEMÁTICOS NA CRIANÇA COM TRANSTORNO DO ESPECTRO AUTISTA
}

\author{
EXECUTION OF EMBLEMATIC GESTURES IN THE CHILDREN WITH \\ AUTISTIC SPECTRUM DISORDER
}

\author{
Cássio Kennedy de Sá Andrade ${ }^{1}$ \\ Giorvan Ânderson dos Santos Alves ${ }^{2}$
}

\begin{abstract}
RESUMO: Nos últimos anos, a teoria multimodal da língua tem despontado como uma das perspectivas de destaque nos estudos em aquisição da linguagem. Sob esta perspectiva, considera-se que a criança, desde muito cedo, começa a se manifestar linguisticamente, utilizando gestos e produções vocais que acontecem principalmente nas interações com o adulto. Tomasello (2003) afirma que, por volta dos nove meses, o bebê, através do olhar e do uso de gestos, começa a se envolver em um tipo de interação por ele chamada de atenção conjunta, que é a capacidade de a criança compartilhar atenção entre seu parceiro de interação e algum objeto que componha a cena interativa. Bruner (1978) aponta o comportamento de atenção conjunta como um dos passos para a habilidade de aquisição da linguagem. Nas crianças com Transtorno do Espectro Autista (TEA), esta habilidade de atenção conjunta pode ser afetada, fazendo com que ocorram atrasos de linguagem. Para que possa interagir, a criança com atraso de linguagem pode recorrer à utilização de mecanismos que ajudem a sustentar suas interações, como os gestos emblemáticos, que são gestos que fazem parte de uma comunidade ou grupo cultural e que podem se tornar convencionalizados de acordo com o contexto ou a rotina de interação (KENDON, 1982; ÁVILA-NÓBREGA, 2017). O estudo apresentado, trata-se de uma pesquisa de cunho qualitativo, do tipo estudo de caso, cujos dados foram coletados junto à uma criança autista de forma naturalística dentro do contexto escolar, através de filmagens da criança e seus parceiros de interação. Através da metodologia utilizada e da análise dos dados coletados, compreende-se que a criança com TEA utiliza os gestos emblemáticos que foram convencionalizados nas interações para alcançar seus objetivos e manter as interações com seus parceiros, o que atesta o caráter multimodal da língua e sua utilização como uma alternativa de comunicação.
\end{abstract}

PALAVRAS-CHAVE: Multimodalidade; Aquisição da Linguagem; Transtorno do Espectro Autista; Gestos Emblemáticos.

ABSTRACT: In recent years, multimodal language theory has emerged as one of the most prominent perspectives in language acquisition studies. From this perspective, it is considered that the child from a very early age begins to manifest linguistically, using gestures and vocal productions that happen mainly in the interactions with the adult. Tomasello (2003) states that, around nine months, the baby, through the look and use of gestures, begins to engage in a type of interaction that he calls joint attention, which is the child's ability to share attention between your interaction partner, and some object that composes the interactive scene. Bruner (1978) points to joint attention behavior as one of the steps for language acquisition ability. In children with Autistic Spectrum Disorder (ASD), this joint attention skill can be affected, causing language delays. In order to be able to interact, a child with a language delay may resort to the use of mechanisms that help to sustain their interactions, such as emblematic gestures that are gestures that are part of a cultural community or group and that can become conventionalized according to the context or the routine of interaction (KENDON, 1982; ÁVILA NÓBREGA, 2017). The present study deals with a qualitative research, of the case study type, whose data were collected from the autistic child in a naturalistic way within the school context, through the filming of the child and his interaction partners. Through the methodology used and the analysis of the data collected, it is understood that the child with ASD uses the emblematic gestures, which were conventionalized in the interactions, to reach their goals and maintain the interactions with their partners, attesting to the multimodal character of the language and its use as an alternative communication.

KEYWORDS: Multimodality; Language Acquisition; Autistic Spectrum Disorder; Emblematic Gestures.

\footnotetext{
1 Mestre e Doutorando em Linguística pelo Programa de Pós-graduação em Linguística (PROLING) da Universidade Federal da Paraíba (UFPB). E-mail: cassio.kennedy@gmail.com;

2 Professor do Departamento de Fonoaudiologia da UFPB; Docente Permanente dos Programas de Pós-graduação em Linguística (PROLING) e em Fonoaudiologia (PPG-FON) da Universidade Federal da Paraíba (UFPB). Email: anderson_ufpb@yahoo.com.br.
} 
Volume 14 - Número 2 - ago/dez de 2019

\section{Introdução}

Dada sua complexidade, o fenômeno da linguagem acaba por se tornar uma área multidisciplinar que envolve diferentes campos do conhecimento, e assim vem ganhando espaço nas discussões linguísticas, filosóficas e psicológicas na tentativa de melhor se compreender seu funcionamento. Nesse diapasão, os estudos em aquisição da linguagem têm por finalidade descobrir de que maneira o indivíduo é capaz de adquirir e utilizar o sistema linguístico.

Atualmente, a proposta da multimodalidade destaca-se, trazendo estudos que contribuem para melhor compreensão acerca do processo de aquisição da linguagem em sua totalidade. Sob a perspectiva multimodal, considera-se que já nos primeiros meses de vida do bebê, as rotinas comunicativas estabelecidas com a mãe mediadas pela voz, pelo olhar e pelos gestos são fundamentais para que a criança desenvolva suas capacidades linguísticas.

É preciso considerar que alguns sujeitos não desenvolvem a linguagem de forma plena, como é o caso de alguns sujeitos diagnosticados autistas ou Transtorno do Espectro Autista (TEA). Esses sujeitos possuem uma série de limitações quanto à capacidade de interagir e se engajar socialmente, e esta seria uma das causas para que estes sujeitos apresentem atrasos na linguagem ou utilizem a linguagem de maneira diferenciada.

Neste trabalho, procura-se desenvolver uma discussão acerca de como o sujeito com TEA possuindo atraso de linguagem é capaz de interagir com seus parceiros para que possa alcançar seus objetivos. Para dar suporte a esta discussão, a teoria da multimodalidade torna-se fundamental, pois através dos dados analisados neste estudo, percebe-se que a utilização dos gestos e do olhar, além de serem ferramentas fundamentais para a aquisição da linguagem pela criança, podem ser também uma alternativa para comunicação, principalmente quando a criança possui atrasos de linguagem.

Inicialmente, serão apresentadas considerações atuais sobre o TEA, logo após será tratada a atenção conjunta e a multimodalidade seguida pela metodologia e apresentação dos dados com destaque para utilização dos gestos emblemáticos utilizados pela criança autista no contexto escolar.

\section{Transtorno do Espectro Autista (TEA): breve apresentação}

Em sua quinta edição publicada em 2013, O Manual Diagnóstico de Transtornos Mentais - DSM-5 trata o autismo enquanto uma categoria dentro do denominado Transtorno do Espectro Autista distúrbio que afeta diretamente a capacidade de socialização do indivíduo afetando o estabelecimento da subjetividade ${ }^{3}$ e o desenvolvimento da linguagem.

O autismo clássico foi inicialmente abordado por Leo Kanner no ano de 1943. Por meio de um estudo feito com 11 crianças com idade entre dois e onze anos pacientes do Johns Hopinks Hospital nos Estados Unidos. Em sua pesquisa, Kanner detectou que estas crianças apresentavam alterações comportamentais e de linguagem com tendência ao isolamento e dificuldade de se engajar em situações cotidianas. Estas crianças também apresentavam uso inadequado da linguagem, olhar vago e resistência ao toque, usavam as pessoas como objetos e utilizavam brinquedos de maneira não convencional, possuíam fixação pelo movimento rotatório e resistência a mudanças na rotina, apresentando também movimentos repetitivos e estereotipados (KANNER, 1966).

\footnotetext{
${ }^{3}$ A subjetividade se estabelece quando a criança passa a diferenciar pessoas de objetos inanimados. Quando a criança percebe o seu parceiro interativo, e compreende suas intenções comunicativas e também situações emocionais (TREVARTHEN et al., 1998).
} 
Dentre estas características, merecem destaque a falta de habilidade em estabelecerem contato afetivo e interpessoal com seus pares e a incapacidade de se relacionar com as outras pessoas. Tais condições estão geralmente presentes na criança autista desde os primeiros anos de vida, podendo, inclusive, ser tidas como um fator para que o processo de aquisição da linguagem ocorra de maneira diferenciada, acarretando prejuízos na comunicação.

Alguns autores indicam que a origem do autismo pode estar relacionada à uma alteração cerebral, especificamente numa área denominada sistema motivacional, em que quaisquer alterações neste sistema resultariam em dificuldades de se relacionar com outros indivíduos (TREVARTHEN et al, 1998). Outra perspectiva também aceita é a de que fatores biológicos e genéticos também estariam relacionados à causa do TEA. Pesquisas demonstraram que cerca de três a dez genes e vários cromossomos podem estar relacionados ao autismo, e que a chance de um irmão de autista também desenvolver o transtorno é 50 vezes maior do que da população em geral (ASSUNÇÃO JR. e KUCZYNSKI, 2007).

Einsenberg e Kanner (1956) já apontavam para a hipótese que o autismo seria resultado de múltiplos fatores. Para os autores, opor fatores hereditários e ambientais consistia em um erro, pois tais conceitos deveriam ser definidos interpenetrando-se. Atualmente, essa é a perspectiva mais aceita, tal ideia salienta que o autismo é um transtorno decorrente de múltiplas causas em que pesam tanto os fatores genéticos e biológicos, como também aspectos ambientais.

O diagnóstico de autismo é feito por meio da observação do comportamento da criança e de uma entrevista com os pais ou responsáveis. Resumidamente, o DSM-5 considera autista o sujeito que apresenta uma díade de características pelas quais é definido o TEA, são elas: a) dificuldade de comunicação e interação social; b) presença de estereotipias e interesses restritos e repetitivos.

A busca pelo diagnóstico é fundamental para que, a partir dele, pais e profissionais passem a lidar com as limitações apresentadas pela criança de forma adequada, possibilitando assim ser desenvolvimento. É preciso atentar que o diagnóstico de TEA não pode ser uma barreira para o tratamento da criança e sim um auxiliar, já que erroneamente tem-se a ideia de que a criança diagnosticada com autismo deve ter sua participação e atuação social limitada.

É importante salientar que diferentes sujeitos, com capacidades e limitações diferentes, tem recebido o mesmo trato por receberem o mesmo diagnóstico de autismo, o que pode fazer com que habilidades individuais presentes em cada sujeito sejam deixadas de lado.

Sobre essa problemática BARROS e FONTE (2016, p. 746) apontam que:

[...] esse conjunto característico do autismo favorece uma concepção prévia de isolamento do autista e de negação de sua linguagem, mantendo o discurso de que a pessoa autista está ausente da possibilidade de linguagem, uma vez que duas das principais características - a dificuldade na comunicação e na interação - são requisitos para a definição de linguagem dentro de uma concepção linguística pautada na relação linguagem e comunicação.

As autoras criticam o posicionamento que impõe que a criança autista estando ausente da comunicação falada e tendo dificuldades de socialização é tratada como sujeito em negação, tal discurso que acaba "colocando o autista no lugar do não, onde nada existe, onde nada seria possível” (BARROS e FONTE, 2016, p. 746).

Tal posicionamento é também adotado neste estudo, uma vez que se torna necessário considerar o sujeito autista para além do diagnóstico, é preciso incentivar sua participação em locais sociais como a escola, por exemplo. É preciso enxergar além das barreiras e das limitações ditadas pelos manuais diagnósticos, que em sua maioria são genéricas e generalizadoras, e que não consideram as capacidades individuais que cada sujeito com TEA pode apresentar. 
Outro aspecto que é preciso destacar é que as crianças com autismo desde muito cedo apresentam alterações no comportamento de atenção conjunta. Em estudo feito por Carpenter e Tomasello (2000) notou-se que estas crianças não compartilham atenção e interesse em interagir e que há alterações relacionados ao olhar referencial (alternância de olhar entre objeto/pessoa), no apontar e em mostrar declarativos, em olhar para onde o outro está olhando/apontando, e no reconhecimento de expressões faciais. Qualquer alteração no comportamento de atenção conjunta, pode ocasionar em dificuldades de adquirir a linguagem, sobre a atenção conjunta trataremos a seguir.

\section{Uma síntese sobre a Atenção Conjunta}

O homem percorreu uma longa jornada evolutiva e transitou nos mais diversos contextos até alcançar o nível de comunicação verbal que tem atualmente. Através da interação com seus semelhantes e da utilização de ferramentas comunicativas tais como gestos e ações, foi que o ser humano desenvolveu sua capacidade de compartilhar e interpretar atividades colaborativas.

Em torno desse mesmo modelo evolucionista/desenvolvimental o bebê atravessa várias fases do desenvolvimento até adquirir a linguagem, e tudo isso se inicia no momento em que é possível perceber suas habilidades em olhar em direção ao outro, retribuir o olhar do outro, mostrar e compartilhar objetos. Quando a criança manifesta esses padrões de comportamento, é observado o comportamento de atenção conjunta.

De acordo com Bruner (1983), é pelos sete meses de idade que a criança começa a estabilizar o comportamento de atenção conjunta e o adulto, nesta situação, tem a função controladora. Aqui, o adulto interage com a criança utilizando a fala e os gestos, e a partir daí, a criança começa a retribuir estas ações, principalmente direcionando o olhar para o foco da cena de atenção conjunta.

Ao se falar em foco dentro da atenção conjunta, vale destacar que outro conceito para atenção conjunta está relacionado à capacidade de colocar a atenção entre um parceiro interacional e um objeto de interesse mútuo, envolvendo, portanto, a coordenação recíproca do adulto e da criança para um foco num terceiro elemento que compõe a cena interativa (TOMASELLO, 1995).

Tomando por base as considerações de Bruner (1983) e Tomasello (1995), pode-se definir a atenção conjunta como a habilidade humana de dividir atenção entre um parceiro social e um objeto, considerando principalmente a alternância de olhar entre o objeto e o interactante. Ainda de acordo com Tomasello (2003), esse comportamento começa a aparecer quando o bebê tem por volta de nove meses de idade, sendo a capacidade de atenção conjunta o canal em que a criança e o adulto estabelecem trocas comunicativas. Destarte, é por meio deste canal que a criança utiliza formas de comunicação não verbal, como o gesto de apontar, a fim de interagir, e o adulto, como detentor da linguagem verbal, irá atuar como sustentador desta interação.

Ao tratar da atenção conjunta torna-se importante pensar no nível de engajamento mútuo estabelecido entre os interactantes, é neste sentido que Melo (2015) e Ávila-Nóbrega (2017) propõem a existência da ação conjunta e da atenção conjunta. Na ação conjunta, a partilha de interesses ocorre muitas vezes de maneira implícita ao passo que na atenção conjunta o objetivo é comum e compatível ao interesse dos sujeitos no momento de interação. De forma mais clara, se considera que, na ação conjunta há intencionalidade compartilhada, porém sem a garantia que ambos os parceiros de interação tenham consciência do objeto compartilhado, ao passo que, na atenção conjunta é necessário que todos os envolvidos na interação estejam mutualmente atentos ao objeto compartilhado, compreendendo assim um processo mais elaborado e de mútuo interesse entre os envolvidos.

Considera-se importante esta distinção "ação/atenção" e a discussão feita pelos autores acerca do tema, porém assunto poderá ser mais aprofundado em outro momento. Por oportuno, é 
Volume 14 - Número 2 - ago/dez de 2019

importante tratar agora que Tomasello (2003) propôs uma classificação para diferentes tipos de atenção conjunta, pois para o autor, este comportamento é um evento que se configura em três formatos definidos por ele como: atenção de verificação, atenção de acompanhamento e atenção direta e que são detalhadas conforme o quadro abaixo:

\section{Quadro 1: Tipos de Atenção Conjunta}

Atenção de verificação: ocorre quando o bebê tem por volta de nove a doze meses de idade e que consiste em uma atividade conjunta, na qual a criança compartilha/verifica a atenção do adulto, ou simplesmente olha para o adulto

Atenção de acompanhamento: ocorre quando a criança tem por volta de onze a catorze meses e caracteriza-se pela capacidade de o bebê acompanhar a atenção que o adulto dirige a entidades distais externas, podendo ocorrer pela simples ação de acompanhar com o olhar e/ou pela indicação com o dedo

Atenção direta: ocorre quando o bebê tem entre treze e quinze meses de idade e se caracteriza, sobretudo, pela presença do gesto de apontar, que pode ser declarativo ou imperativo, quando a criança é capaz de direcionar a atenção do adulto para entidades distais externas.

*Quadro formulado pelo autor de acordo com os tipos de atenção conjunta elaborados por Tomasello (2003).

Através do quadro, nota-se que a participação da criança gradualmente se torna mais evidente e ativa, começando com o simples olhar, passando para a indicação com o dedo até chegar no gesto de apontar de modo declarativo e/ou imperativo.

Tratando-se de crianças com TEA, este ciclo de desenvolvimento da atenção conjunta ocorre de forma diferente do da criança com desenvolvimento típico, já que a criança autista não se engaja socialmente com outras pessoas e não se envolve em interações diádicas (entre a criança e o adulto) nem triádicas (entre a criança, o adulto e um terceiro elemento), causando assim prejuízos à comunicação verbal (MUNDY e SIGMAN, 1989).

Nesta apresentação sobre atenção conjunta, evidencia-se bastante o fato de a criança seguir passos em direção à comunicação verbal. Através da atenção conjunta e das interações que ocorrem através dela, criança e adulto se engajam numa relação permeada pela utilização de gestos, olhares, trocas de sorrisos e vocalizações - elementos que compõem a multimodalidade, que passa a ser apresentada a seguir.

\section{A multimodalidade: realçando os gestos emblemáticos}

A proposta de pesquisa ora apresentada trata a linguagem em sua constituição, o que significa dizer que seu caráter comunicativo é atravessado por diferentes elementos que a transformam em um complexo emaranhado de artefatos que acabam por constituir a matriz da linguagem e que estão presentes nas mais diversas formas comunicativas.

Kendon (1982) e McNeill (1985) assinalam que a multimodalidade representa um conjunto de ferramentas consideradas multimídia, ou seja, um cabedal de recursos que estão à disposição dos falantes para serem utilizados juntamente com a linguagem verbal. Sob esta perspectiva, a matriz da linguagem se constitui pela presença das produções vocal e gestual que, ao serem integradas, formam um sistema de significação que contribui para produção de sentido na relação entre os sujeitos.

É necessário frisar que a proposta multimodal se encaixa na perspectiva funcionalista dos estudos linguísticos, ou seja, tem uma base sociointeracional que destaca principalmente seu uso em situações reais de comunicação como forma de manutenção da interação entre os participantes.

Sendo assim, a comunicação humana é constituída por diferentes elementos tais como: fala, mímicas faciais, gestos e mudanças corporais, de modo que, na interação baseada na fala e/ou gestualidade, um ou outro desses elementos pode ser mais saliente, dependendo do contexto interativo e dos sujeitos envolvidos (BARROS e FONTE, 2016). 
Volume 14 - Número 2 - ago/dez de 2019

Para a criança com dificuldades ou atraso de linguagem, a multimodalidade servirá como principal canal comunicativo, como é o caso das crianças com TEA. Sobre este aspecto, Barros e Fonte (2016, p. 751) apontam que:

No caso específico de uma criança autista em que a linguagem pode ser caracterizada pela ausência de oralidade, atraso na aquisição, presença de alterações sintáticas e semânticas, o modo gestual da linguagem surge como aspecto relevante na constituição do sujeito e na significação da linguagem.

Conforme posto acima, a criança autista com atraso na linguagem pode recorrer à utilização de outra forma de comunicação para alcançar seus objetivos, ela poderá utilizar inclusive gestos, ou qualquer outro recurso que sirva alternativa à comunicação, é neste momento que o caráter multimodalidade da língua torna-se essencial, uma vez que passa a ser utilizado e ressignificado dentro de um contexto em que a comunicação falada não é possível.

Em referência à multimodalidade, McNeill (1992) elenca alguns recursos multimodais como a postura corporal, conhecimento partilhado, conhecimento de mundo, direcionamento do olhar, prosódia, expressões faciais em geral, o espaço etc.. McNeill também indica que gesto e fala formam um par indissociável, e que a presença dos gestos ao longo da fala determina a coordenação de dois tipos de pensamento, o imagístico e o sintático (MCNEILL, 1985).

Ao revisar os estudos de Adam Kendon, David McNeill (1985) destaca a abordagem gestual proposta por Kendon destacando sobretudo a influência dos gestos em relação ao discurso. Notadamente, McNeill (1985) apresenta o "Contínuo de Kendon", denominação dada por ele ao conjunto de gestos elaborado por Kendon (1982) que destaca principalmente a gesticulação, a pantomima, os emblemas e a(s) línguas(s) de sinais.

Quadro 2: Definição dos gestos que compõem o Contínuo de Kendon

\begin{tabular}{|l|l|}
\hline Gesticulação & $\begin{array}{l}\text { Caracteriza-se como os gestos que acompanham o fluxo da fala, envolvendo braços, } \\
\text { pernas, movimentos de cabeça, pescoço e postura corporal, possui marcas da comunidade } \\
\text { de fala e marcas do estilo individual de cada um. }\end{array}$ \\
\hline Pantomima & $\begin{array}{l}\text { São gestos que 'simulam' ações ou personagens executando ações, é a } \\
\text { representação de um ato individual, tem um caráter de narrativa, pois envolve uma } \\
\text { sequência de micro ações. }\end{array}$ \\
\hline Emblema & $\begin{array}{l}\text { Também chamados de gestos emblemáticos, são aqueles determinados culturalmente (são } \\
\text { convencionais) tais como o uso, em nossa cultura, do gesto que envolve a mão fechada e } \\
\text { polegar levantado significando aprovação. }\end{array}$ \\
\hline Língua de sinais & $\begin{array}{l}\text { Sistema linguístico próprio de uma comunidade; no nosso caso, a Língua Brasileira de } \\
\text { Sinais (LIBRAS). }\end{array}$ \\
\hline
\end{tabular}

*Quadro elaborado pelo autor baseado em CAVALCANTE (2009, p. 156).

Com essa breve apresentação sobre os gestos tratados no contínuo, destacamos os emblemas ou gestos emblemáticos, pois são gestos que podem ser manifestados na presença ou ausência da fala, sendo parcialmente convencionais uma vez que se constroem socialmente e tem significação própria dentro de uma cultura (McNeill, 2000). Há a possibilidade de que a criança autista, estando inserida num contexto sociointeracional, passe a utilizar esse tipo de gesto para conseguir interagir.

De acordo com Levy (1987) os emblemas podem ser produzidos em várias circunstâncias, destacando sua utilização em substituição ao discurso verbal, principalmente em momentos em que não é possível utilizar a palavra, como, por exemplo em locais barulhentos; quando indivíduos estão distantes; quando indivíduos não falam a mesma língua; ou quando há ocorrência de deficiências sensoriais, como por exemplo, os surdos que utilizam a língua de sinais que é caracteristicamente composta por emblemas.

O mesmo autor também destaca que uma das características que distingue os emblemas de outros gestos é a sua capacidade de substituir palavras. Ele considera que durante a 
conversação, a gesticulação utilizada junto a fala não tem um significado preciso, não podendo substituí-la, de modo que só podem ser produzidos quando se discorre verbalmente, enquanto que os emblemas realçam os sentidos das palavras (LEVY, 1987).

$\mathrm{Na}$ busca de uma boa definição sobre gestos emblemáticos, encontrou-se uma precisa conceituação formulada por Ekman e Friesen (1972) que, após estudarem uma série de diferentes comportamentos não verbais, definiram os emblemas como:

\begin{abstract}
Emblemas são movimentos não verbais que têm um significado verbal preciso, consistindo normalmente numa ou duas palavras ou numa fase. O seu significado é conhecido por todos ou pela maioria dos indivíduos de uma cultura, sub-cultura ou grupo. São quase sempre produzidos voluntariamente e com a intenção de enviar uma mensagem específica para outros indivíduos. O receptor do Emblema reconhece, normalmente, que este lhe foi deliberadamente enviado. Outra característica dos Emblemas é a possibilidade de serem substituídos por uma palavra ou frase, sem que se modifique o diálogo (EKMAN e FRIESEN, 1972 apud LEVY, 1987).
\end{abstract}

Em uma concepção mais atual sobre os emblemas, Ávila-Nóbrega (2017) assinala que estes são tipos de gestos que podem fazer parte de uma comunidade cultural, microcultura, grupo de amigos, sala de aula, comunidade religiosa, atendimento terapêutico, etc.. Por serem segmentados e possuírem caráter mais metafórico, os gestos emblemáticos tem seu conteúdo semântico favorecido dentro de sua cultura ou microcultura (ÁVILA-NÓBREGA, 2017).

É com base nestas concepções de emblema que este trabalho se propõe a analisar a performance gestual da criança com TEA dentro do contexto escolar, ressaltando os momentos em que os gestos utilizados pela criança são ressignificados pelos seus parceiros de interação, tornando-se assim convencionalizados, cujo sentido ocorre especialmente dentro deste contexto específico e com a finalidade de alcançar objetivos e estabelecer a comunicação.

\title{
5 Metodologia empregada
}

Os dados apresentados neste trabalho são resultado de um estudo realizado pelo autor no ano de 2016 e que tinha por finalidade observar e analisar a multimodalidade utilizada por uma criança autista no contexto escolar. Tal pesquisa se filia ao LAFE (Laboratório de Aquisição de Fala e Escrita) do PROLING/UFPB (Programa de Pós-graduação em Linguística da Universidade Federal da Paraíba). Esta pesquisa encontra-se totalmente amparada pelos critérios éticos de pesquisa envolvendo seres humanos, tendo sido aprovado pelo Comitê de Ética em Pesquisa da UFPB sob o número de protocolo 049/16, CAAE: 53711916.7.0000.5188.

$\mathrm{O}$ estudo ora apresentado, trata-se de uma pesquisa de cunho qualitativo longitudinal do tipo estudo de caso, envolvendo uma criança do sexo masculino com 5 anos de idade com diagnóstico de autismo e seus parceiros de interação.

A coleta de dados ocorreu por meio da observação e filmagem das cenas de interação protagonizadas pela criança com TEA, tal coleta foi realizada semanalmente durante quatro meses em uma escola da rede municipal da cidade de João Pessoa - PB.

Após a coleta, os dados foram analisados e transcritos por meio da utilização do software ELAN (Eudico Linguistic Annotator), uma ferramenta de transcrição que possibilita a anotação dos diferentes recursos multimodais capturados em vídeo no momento exato em que eles acontecem. Para este trabalho, optou-se por registrar e transcrever os gestos e vocalizações utilizados pelos participantes nos mais variados ambientes da escola, porém o corpus deste artigo é formado por 3 fragmentos que foram selecionados com vista a apresentar a execução dos gestos emblemáticos pela criança dentro das cenas de atenção conjunta. Portanto, o emblema é aqui tratado como a principal categoria de análise cuja base teórica está 
Volume 14 - Número 2 - ago/dez de 2019

fundamentada no Continuum de Kendon anteriormente apresentado (KENDON, 1982; MCNEILL, 2000).

Os fragmentos serão apresentados em quadros que delimitam o tempo de ocorrência da interação, os gestos emblemáticos utilizados que estão realçados em cinza e fala dos interactantes, marcada pela presença de aspas, como se verá a seguir.

\section{A execução dos gestos emblemáticos pela criança com TEA}

A criança participante deste estudo, com idade de cinco anos, foi inserida pela primeira vez numa sala de aula no mesmo ano de ocorrência deste estudo. Em conversas informais com a professora e a cuidadora, o pesquisador foi informado que inicialmente o menino, chamado aqui de (M), tinha muita resistência em permanecer na sala de aula, chegando a chorar e gritar até ser retirado da sala. Através da organização da rotina na sala de aula, promovida pela professora, e de uma readaptação por parte dos alunos, o menino foi se adaptando à sala e a escola, o que é considerado um avanço nas palavras da professora e cuidadora.

Após a adaptação de $\mathrm{M}$. à sala de aula, notou-se que ele, ao não se comunicar através da fala, passou a utilizar os gestos para alcançar seus objetivos nos diferentes contextos da escola, e isso é o que será apresentado nos três fragmentos que se seguem.

Quadro 3: Fragmento 1

\begin{tabular}{|l|l|l|l|l|}
\hline Tempo inicial & Tempo final & Gesto da criança & Gesto do Pesquisador & Fala da cuidadora \\
\hline 00:00:04.237 & $00: 00: 20.020$ & $\begin{array}{l}\text { Pega na mão do } \\
\text { pesquisador levando- } \\
\text { o até a porta da sala }\end{array}$ & $\begin{array}{l}\text { Pega na mão da } \\
\text { criança caminha } \\
\text { junto a M. e abre a } \\
\text { porta da sala. }\end{array}$ & $\begin{array}{l}\text { "Ele vai te levar lá na } \\
\text { sala de Nildinha." }\end{array}$ \\
\hline
\end{tabular}

Fonte: o autor

Com a apresentação do quadro acima, torna-se importante detalhar melhor o contexto do qual foi extraído esse fragmento. $\mathrm{O}$ fato acima aconteceu na sala de aula a qual a criança faz parte, participaram dessa cena o pesquisador e a cuidadora da criança. Incialmente a criança estava observando uma atividade que a professora estava realizando, logo em seguida voltouse ao pesquisador pegando na mão dele e levando-o até a porta da sala, o pesquisador ao chegar até a porta, abre-a e os dois saem juntos.

É importante notar que o simples fato de pegar na mão do pesquisador já denota uma intencionalidade por parte da criança, ou seja, a criança marca seu lugar na linguagem através do gesto, que é reconhecido pelo seu parceiro que identifica a intenção da criança e entende esta ação enquanto um pedido para sair da sala.

A caracterização desta ação como gesto emblemático acontece por esta se tratar de ato que denota um chamado, ou seja, este gesto é entendido pelos interactantes dentro de um contexto específico de significação. Outro fato importante a ser considerado é que este "chamado" ocorre dentro de uma cena de atenção conjunta do tipo atenção direta em seu modo imperativo, pois se entende o gesto também como um pedido de auxílio para a execução de uma tarefa que, neste caso, seria abrir a porta para sair.

No fragmento a seguir ocorre outra configuração do gesto emblemático, dessa vez no momento em que a criança pega e segura a bolsa da professora, a ação é reconhecida pela professora e pela cuidadora como uma forma da criança indicar que quer sair da sala. 
Volume 14 - Número 2 - ago/dez de 2019

Quadro 4: Fragmento 2

\begin{tabular}{|l|l|l|l|l|}
\hline Tempo inicial & Tempo final & Gesto da criança & Fala da cuidadora & $\begin{array}{l}\text { Fala e gesto da } \\
\text { professora }\end{array}$ \\
\hline $00: 00: 12.679$ & $00: 00: 36.703$ & $\begin{array}{l}\text { Com as duas mãos, } \\
\text { pega e segura a bolsa } \\
\text { da professora, ainda } \\
\text { segurando a bolsa, } \\
\text { estende a mão } \\
\text { direita, pega e segura } \\
\text { a mão esquerda da } \\
\text { professora. }\end{array}$ & $\begin{array}{l}\text { "Vai pra onde hein } \\
\text { M.?" } \\
\text { pra trás (fala dirigida } \\
\text { ao pesquisador)." } \\
\text { Segura a mão direita } \\
\text { da criança. "Vai para } \\
\text { onde? Ainda tem } \\
\text { aula da tia Camile de } \\
\text { educação artística." }\end{array}$ \\
\hline
\end{tabular}

Fonte: o autor

O fragmento acima foi extraído de um momento maior em que M. estava na sala de aula sentado na sua carteira até o momento em que se levanta caminha até a mesa da professora e pega uma bolsa que estava sobre a mesa. Ao pegar a bolsa, a professora se dirige ao pesquisador e explica a intenção da criança ao falar "É pra me levar pra trás", em seguida se dirige a criança perguntando "Vai para onde? Ainda tem aula da tia Camile de educação artística.". A ação da criança ao pegar a bolsa também é reconhecida pela cuidadora que estava presente no momento e que já sabendo da intenção da criança também pergunta "Vai pra onde hein M.?".

$\mathrm{O}$ gesto emblemático em sua caracterização se estabelece enquanto um gesto culturalmente marcado ou convencionalizado num contexto menor, como, por exemplo, na sala de aula. O reconhecimento da intencionalidade entre os parceiros de interação só acontece quando todos os envolvidos na cena estão cientes dos propósitos que ali podem ser estabelecidos, assim sendo, a professora reconhece a intencionalidade da criança no momento da execução do gesto "pegar a bolsa", o que já tinha sido relatado pela mesma anteriormente. Em uma conversa informal entre o pesquisador e a professora, a educadora informou que muitas vezes a criança executa o ato de pegar a bolsa, como um modo de indicar que deseja sair do local, caracterizando tal ato como um gesto emblemático que foi convencionalizado entre a professora e a criança.

A seguir, no quadro 5 é mostrado o terceiro e último fragmento.

Quadro 5: Fragmento 3

\begin{tabular}{|l|l|l|l|}
\hline Tempo inicial & Tempo final & Gesto da criança & Fala da cuidadora \\
\hline 00:00:00.600 & $00: 00: 09.810$ & $\begin{array}{l}\text { Com a mão direita, pega e segura } \\
\text { copo }\end{array}$ & $\begin{array}{l}\text { "Quer água, quer? Água?” Pega } \\
\text { a garrafa com a mão direita e em } \\
\text { seguida tira a tampa destorcendo, } \\
\text { em seguida coloca água no copo } \\
\text { da criança. "Deixa eu colocar a } \\
\text { água? pera aí, pera aí, pera aí, } \\
\text { pera aí...”" }\end{array}$ \\
\hline
\end{tabular}

Fonte: o autor

O fragmento acima foi extraído de um contexto em que a criança e a cuidadora estão sentados numa mesa no pátio da escola durante o intervalo das aulas, junto a criança e a cuidadora está a lancheira da criança contendo pipoca e biscoitos, um copo e uma garrafa com água.

A interação se inicia no momento em que a criança estende o braço em direção a um copo que está sobre a mesa, pega e deixa próximo a si. Ao observar esta ação, a cuidadora percebe a intenção de M., que era que ela colocasse água no copo para que ele pudesse beber. A ação da criança vem seguida do reconhecimento pelo seu parceiro, que, através da fala, deixa claro o entendimento sobre aquele gesto ao perguntar "Quer água, quer? Água?” e seguida da ação de 
Volume 14 - Número 2 - ago/dez de 2019

colocar água acompanhada de outra fala "Deixa eu colocar a água? pera aí, pera aí, pera aí, pera aí...".

Esta interação ocorre dentro e uma cena de atenção conjunta do tipo atenção direta, na qual há presença de um gesto imperativo, que aqui se caracteriza no ato da criança pegar o copo, indicando um pedido de auxílio para que possa tomar água. A ação da criança nesta cena é tão bem executada que o gesto de pegar o copo é imediatamente reconhecido pela cuidadora que prontamente atende ao objetivo da criança. Para este caso, é importante lembrar que a atenção direta não necessariamente precisa vir acompanhada do gesto de apontar. Segundo Ávila Nóbrega (2010), a atenção direta também se estabelece quando ocorre algum gesto ou ação que signifique um tipo de apontar e, neste caso, ocorre através da ação da criança ao pegar o copo.

\section{Algumas considerações}

A multimodalidade enquanto campo de estudo na pesquisa em aquisição da linguagem engloba uma série de elementos que estão presentes nas interações do bebê desde os primeiros dias de vida, dentre esses elementos pode-se destacar os gestos, a troca de olhares e as vocalizações que conjuntamente formam a base das interações necessárias ao desenvolvimento da linguagem.

Com o intuito de compreender melhor o fenômeno da linguagem em suas mais diversas configurações, a perspectiva multimodal da língua foi aqui abordada no sentido de melhor detalhar a manifestação linguística de uma criança com diagnóstico de TEA. O autista quando possui atraso de linguagem é tratado muitas vezes como um sujeito nulo de participação social, uma vez que não está apto à linguagem verbal, diferente da maioria dos demais indivíduos. Observando as interações da criança autista no contexto escolar, é possível notar que sua participação na língua ocorre de maneira diferente, e que suas manifestações gestuais são carregadas de significação que só precisam de um parceiro de interação mais sensível e atento às suas especificidades comunicativas.

O estudo da utilização dos gestos na aquisição da linguagem, permite que esta mesma abordagem seja tomada sobre outras perspectivas. Neste artigo, abordamos os gestos emblemáticos como uma ação carregada de significado e que possibilita à criança com atraso de linguagem uma alternativa à sua comunicação. As rotinas interacionais estabelecidas com a criança autista na sala de aula possibilitaram com que seus parceiros de interação percebessem que ações como pegar na bolsa, pegar no copo e pegar na mão possuem uma significação específica e que só funcionam dentro de um contexto específico, sendo esta a forma que se estabelecem os emblemas.

Por fim, nota-se que a performance gestual da criança com TEA é carregada de uma significação construída nas cenas de atenção conjunta. A manifestação dos emblemas pela criança exprime um significado verbal preciso que é partilhado com os demais participantes da interação por meio da atenção conjunta, através da qual há partilha da intencionalidade dos sujeitos que vão construindo os gestos emblemáticos como formas precisas de comunicação e importante mecanismo para iniciar e manter as interações.

\section{Referências}

ASSUNÇÃO Jr., F.B.; KUCZYNSKI, E. Autismo - conceito e diagnóstico. In: ASSUNÇÃO Jr., F.B e KUCZYNSKI, E. (Orgs). Autismo infantil: novas tendências e perspectivas. São Paulo: Atheneu, 2007. p.1-17 
Volume 14 - Número 2 - ago/dez de 2019

ÁVILA-NÓBREGA, P. V. O Sistema de referenciação multimodal de crianças com síndrome de down em engajamento conjunto. Tese de doutorado. Universidade Federal da Paraíba: João Pessoa, 2017.

Dialogia mãe-bebê: a emergência do envelope multimodal em contextos de atenção conjunta. Dissertação de mestrado. Universidade Federal da Paraíba, João Pessoa, 2010.

BARROS, I. B. R.; FONTE, R. F. L. Estereotipias motoras e linguagem: aspectos multimodais da negação no autismo. Revista Brasileira de Linguística Aplicada, v. 16, n. 4, p. 745-763, 2016.

BRUNER, J. Childs Talk. Oxford: OUP, 1983

CAVALCANTE, M. C. B. Rotinas Interativas mãe-bebê: constituindo gêneros do discurso. In: Investigações, UFPE, v. 21, 2009. p. 153-170

EISENBERG, L.; KANNER, L. Early infantile autism. In: American jornal of othopsychiatry, v. 26, n. 3, p. 556-566, 1956.

EKMAN P.; FRIESEN W. Hand MoVements. In: Journal of Communication, 1972, vol. 22, p. 353-374.

KANNER, L. Psiquiatría infantil. Buenos Aires: Paidos e Psique, 1966.

KENDON, A. The study of gesture: some observations on its history. In: Researches

Semiotique/Semiotic Inquiry, 1982, vol. 2 (1), p. 25-62.

LEVY, Pedro M. Emblemas-uma categoria de comportamentos não verbais. In: Análise Psicológica, 1987, vol. 5, p. 295-304.

MCNEILL, D. Language and gesture. Cambridge: Cambridge University Press, 2000.

Hand and mind: what gestures reveal about thought. Chicago: The University of

Chicago Press, 1992. 350-371.

So you think gestures are nonverbal? In: Psychological review. 1985, vol. 92 (3), p.

MELO, G. M. L. S. Cenas de atenção conjunta entre professoras e crianças em processo de aquisição de linguagem. Tese de Doutorado. Universidade Federal da Paraíba: João Pessoa, 2015.

MUNDY, P.; SIGMAN, M. Specifying the nature of the social impairment in autism. In: G. Dawson (Org.). Autism: New perspectives on nature, diagnosis, and treatment. New York: Guilford, 1989. p. 3-21.

OLIVEIRA, S. M. A clínica do autismo sob uma perspectiva desenvolvimentista: o papel do engajamento afetivo no desenvolvimento da comunicação e da linguagem. Dissertação de Mestrado. PUC-RJ, 2009.

TOMASELLO, M. Origens culturais da aquisição do conhecimento humano. Tradução de Cláudia Berliner. São Paulo: Martins Fontes, 2003.

Joint attention as social cognition. In: C. Moore P. J. Dunham (Eds.), Joint

attention: Its origins and role in development. Hillsdale: Lawrence Erlbaum Associates, 1995, p. 103-130.

TREVARTHEN, C; AITKEN, K.; PAPOUDI, D.; ROBARTS, J. Children with autism. Diagnosis and interventions to meet their needs. 2. ed. London: Jessica Kingsley, 1998. 